\title{
Weaning success among COPD patients following ventilator care bundle application
}

\author{
Eman Yasser Hammouda*1, Hanaa Hussein Ahmed ${ }^{1}$, Amr A. Moawad ${ }^{2}$, Nahed Attia Kandeel \\ ${ }^{1}$ Critical Care and Emergency Nursing, Faculty of Nursing, Mansoura University, Egypt \\ ${ }^{2}$ Chest Medicine, Faculty of Medicine, Mansoura University, Egypt
}

Received: December 22, 2021

DOI: $10.5430 / \mathrm{cns} . v 10 \mathrm{n} 1 \mathrm{p} 1$
Accepted: February 23, $2022 \quad$ Online Published: March 2, 2022

URL: https://doi.org/10.5430/cns.v10n1p1

\begin{abstract}
Objective: Several studies evaluated the effectiveness of the ventilator care bundle in reducing the occurrence of ventilatorassociated pneumonia. The ventilator care bundle efficacy in early mechanical ventilation weaning has not been adequately assessed. The study aimed to investigate the weaning success among chronic obstructive pulmonary disease (COPD) patients following ventilator care bundle application.

Methods: This study is quasi-experimental, recruiting 80 mechanically ventilated COPD patients (40 patients for each bundle and control group). It was conducted at the respiratory intensive care units (ICUs) at Mansoura University Hospital, Egypt. Data were collected using a mechanically ventilated patient (MVP) assessment tool, a ventilator care bundle compliance checklist, and MVP evaluation tools based on the Burns' Wean Assessment Program (BWAP) checklist and the patient's ventilation indicators. Results: The results revealed that almost $75 \%$ of the bundle group was successfully weaned from invasive mechanical ventilation at the first attempt of the spontaneous breathing trial compared with $32.5 \%$ of the control group. The ventilation duration and length of ICU stay were reduced in the bundle compared with the control group.

Conclusions: The bundle group demonstrated higher weaning scores than the control group. Therefore, we recommend the integration of the ventilator care bundle in the weaning trial of MVPs to accelerate weaning and reduce the duration of mechanical ventilation.
\end{abstract}

Key Words: Ventilator care bundle, Chronic obstructive pulmonary disease, Weaning

\section{INTRODUCTION}

Invasive mechanical ventilation (IMV) is one of the technological assistance devices and a life-saving modality in the ICUs. ${ }^{[1]}$ According to some studies, IMV is significantly increased in the ICU for the management of patients with chronic obstructive pulmonary disease (COPD) associated with respiratory failure. ${ }^{[2,3]}$ Additionally, Brown et al. ${ }^{[4]}$ stated that COPD patients often require ICU admission during acute exacerbations, which are associated with a high level of morbidity and mortality.
The Global Initiative for Chronic Obstructive Lung Disease (GOLD) defined COPD as a common, preventable, and treatable disease that is characterized by chronic reversible airflow limitation, inability to breathe out fully, and air trapping. ${ }^{[5]}$ According to the World Health Organization (WHO, 2021), ${ }^{[6]}$ COPD is the third leading cause of death worldwide, causing 3.23 million deaths in 2019. Using recent evidence, noninvasive positive-pressure ventilation is the first choice in treating COPD with respiratory failure. Moreover, IMV may be required for severely diseased patients. ${ }^{[7,8]}$

*Correspondence: Eman Yasser Hammouda; Email: emanyasser@mans.edu.eg; Address: Critical Care and Emergency Nursing, Faculty of Nursing, Mansoura University, Egypt. 
Although IMV is often a life-saving procedure for COPD patients, its application is associated with significant complications. ${ }^{[9]}$ Among these complications is VAP, ${ }^{[10]}$ ventilatorinduced lung injury, weaning failure, ${ }^{[11]}$ deep vein thrombosis, ${ }^{[12]}$ and peptic ulcers. ${ }^{[9]}$

Hence, weaning should be initiated as soon as the patient's condition stabilizes, and the underlying respiratory disorder begins to improve. ${ }^{[13]}$ The weaning process aims to gradually withdraw IMV and resume spontaneous breathing. ${ }^{[14]}$ The weaning failure rate is higher in COPD patients than in other patients. This can be attributed to the underlying pathophysiology of the disease. In COPD patients with acute respiratory failure, dynamic hyperinflation and the generation of intrinsic positive end-expiratory pressure are the main factors that cause increased intrathoracic pressure, which leads to increased work of breathing, asynchrony, dyspnea, and hemodynamic deterioration. ${ }^{[15]}$

Thus, the main challenge for CCNs when caring for MVPs is weaning their patients from ventilatory support successfully. Assessing patients' readiness for weaning is the initial step for disconnecting the patient from the IMV. According to BWAP checklist, the weaning criteria include reversal of the indication for IMV, adequate gas exchange, the ability to initiate a spontaneous breath, stable hemodynamic status, adequate respiratory efforts, absence of profuse bronchial secretions, and appropriate level of anxiety and nervousness. ${ }^{[16]}$

Additionally, to achieve the weaning success goal, the Institute for Healthcare Improvement (IHI, 2012) ${ }^{[17]}$ introduced an evidence-based ventilator care bundle (VCB) practice to prevent complications related to $\mathrm{MV}$ and improve patient outcomes. The VCB includes a small, straightforward set of evidence-based practices that should be performed collectively and constantly. It encompasses 6 elements, including elevation of the patient's head to $30^{\circ}-45^{\circ}$, oral care with Chlorhexidine, daily sedation vacation, assessing the weaning readiness, peptic ulcer prophylaxis (PUP), and deep vein thrombosis prophylaxis. ${ }^{[17]}$

Critical care nurses (CCNs) are the cornerstone of overall patient care from admission until discharge. They play a variety of important roles in preventing ventilator complications including caregivers, educators, managers, coordinators, and evaluators. It is clearly understood that most of the VCB measures are closely related to nursing interventions. ${ }^{[18]} \mathrm{Be}-$ sides, CCNs are particularly well placed to take the lead in the healthcare team in implementing the VCB. ${ }^{[19]}$ A recent study was conducted by Dumbre, ${ }^{[20]}$ who suggested that the improvement of patient outcomes was dependent on CCNs' performance and adherence to VCB practices.

\subsection{Significance of the problem}

Even though the weaning process is the fundamental phase that enables the resumption of physiological respiratory function, sometimes it is associated with weaning failure. ${ }^{[14]} \mathrm{A}$ recent prospective study was conducted in Egypt to assess the MVPs for the predictive value of the integrated weaning indices. They found that approximately $41.2 \%$ of COPD patients failed to wean. ${ }^{[21]}$ This is in agreement with another Egyptian study which reported that $54.2 \%$ of mechanically ventilated COPD patients were unable to wean from the first spontaneous trial. ${ }^{[22]}$ Moreover, prolonged ventilation is associated with many complications such as muscle weakness, pressure ulcers, bacterial nosocomial sepsis, pulmonary embolism, and hyperactive delirium. ${ }^{[23]}$ It is also associated with increased length of hospital stay after ICU discharge, with higher costs. ${ }^{[23]}$

Therefore, the VCB was introduced to prevent such complications, bring best practices to the process of weaning, and improve patients' outcomes. ${ }^{[17]}$ Recent studies have demonstrated the significant VCB advantages in reducing VAP incidence. ${ }^{[24-28]}$ However, there is little evidence regarding the effectiveness of implementing the VCB on the early weaning of MVPs in Egypt. This inspired us to conduct this study to address this issue and contribute to the body of knowledge related to MVP weaning.

The study aimed to investigate the weaning success among COPD patients following VCB application.

\subsection{Research hypothesis}

Mechanically ventilated COPD patients who receive the VCB practices will have higher weaning scores, shorter ventilation duration, and fewer ICU days than patients who receive routine nursing care.

\section{Methodology}

\subsection{Research design}

The present study used the quasi-experimental research design. This is the best design to test the effect of an intervention on the target population without random assignment. ${ }^{[29]}$

\subsection{Setting}

The present study was conducted in the Respiratory ICUs affiliated with Mansoura University Hospital, Egypt. It includes two units, one with seven beds and the other with six. COPD, pneumonia, and obstructive sleep apnea (OSA) are the most common diseases in these units.

\subsection{Participants}

A purposive sample of 80 patients was enrolled in this study from the respiratory ICUs. The sample size was calculated 
considering the level of significance (5\%), power (80\%), and sample size is (see Equation 1):

type of test (two-sided). The formula for calculating the

$$
n=\frac{2\left(z_{\frac{\alpha}{2}}+z_{\beta}\right)^{2} \times p(1-p)}{\left(p_{1}-p_{2}\right)^{2}}=\frac{2(1.96+0.84)^{2} \times 0.233(1-0.233)}{(0.366-0.010)^{2}}=39.6
$$

The sample size was 80 based on the previous formula. Eligible patients were divided randomly into two groups (control and bundle groups). The control group received routine ICU care, whereas the bundle group received evidence-based VCB practices. The eligibility criteria included COPD patients of both genders who were admitted to respiratory ICUs and required IMV. The exclusion criteria were patients who were mechanically ventilated because of acute respiratory failure secondary to causes other than COPD (e.g., myopathy, OSA, pneumonia, congestive heart failure, pneumothorax, chest trauma, and acute lung injury/acute respiratory distress syndrome).

\subsection{Tools}

Three tools were used to collect data in the present study as follows:

\subsubsection{Tool I: Mechanically ventilated patient's assessment tool}

This tool was developed by the principal researcher (PR) after reviewing related literature ${ }^{[30-32]}$ aiming to assess patients' demographic characteristics and health-relevant data. The tool included the patient's age, gender, education level, occupation, smoking habits, date of ICU admission, medical diagnosis, comorbidity, and consciousness level based on the Glasgow coma scale. ${ }^{[33]}$ It also covered participants' healthrelevant data including respiratory examination, ventilator profile, cardiovascular assessment, nutritional assessment, and measured the patient's agitation or sedation level using the Richmond Agitation Sedation Scale. ${ }^{[34]}$

\subsubsection{Tool II: Ventilator bundle compliance checklist}

This tool was adopted from evidence-based recommendations included in the VAP prevention clinical practice guideline which was developed by the IHI. ${ }^{[17]}$ We added airway care which is a highly performed procedure in respiratory ICUs. Nevertheless, there is no available protocol or standard of care for CCNs in the study setting to follow when performing airway care (oral suctioning, tracheal suctioning, ventilator circuit care, endotracheal tube securing, and chest physiotherapy). Thus, the VCB was used in the present study included seven interventions (head-of-bed elevation of $30^{\circ}-45^{\circ}$, oral care with chlorhexidine $/ 8$ hrs., conducting a daily sedation vacation, assessing the patients' readiness to wean, performing airway care, providing peptic ulcer pro- phylaxis, and applying deep venous thrombosis prophylaxis). The VCB components were checked for eligible patients from the IMV initiation until extubation. The bundle was only considered compliant if all items were completely applied. ${ }^{[17]}$

\subsubsection{Tool III: Mechanically ventilated patient's evalua- tion tool}

This tool included two parts. Part 1 is the BURNS wean assessment program checklist. This part was adopted from Burn (1990) and was used to systemically evaluate and track the weaning progress of the MVPs. It included 26 items, of which 12 items assessed the patient's general measurement and 14 items monitored the patients' respiratory function. The response to each component of these subscales was "yes", "no" or "not assessed". It was calculated by dividing the number of "yes" responses by 26 thresholds. A BURNS wean assessment program (BWAP) score of $\geq 65 \%$ was considered weaning probable, whereas $<65 \%$ was considered weaning improbable. The validity of this tool has been investigated for 5 years in ICUs and shows that its application leads to successful weaning from IMV in $88 \%$ of patients. ${ }^{[16]}$ Additionally, the Cronbach's alpha coefficient for this tool was 0.91 , indicating that the tool was reliable. ${ }^{[35]}$ Part 2 is the patient's ventilation indicators. This part was developed by the PR after reviewing related literature. ${ }^{[36,37]}$ It was used to evaluate the VCB effect on patients' ventilation status. It included ventilation duration, length of ICU stays, and the outcome of the weaning process (success, delay, or failure).

\subsection{Validity and reliability}

The validity of the tools was ascertained by a group of seven experts in the fields of medical and nursing. Their opinions were elicited regarding the format, layout, relevancy, accuracy, and consistency of the tools. Tool III part 1 was adopted and has been extensively used in several studies, suggesting its validity. The overall reliability of tools was tested by using a special case of Cronbach's Alpha test. The reliability of tools I, II, and III part 2 was $0.943,0.921$, and 0.895 respectively, indicating that the tools were reliable.

\subsection{Ethical considerations}

Ethical approval was obtained from the research ethics committee of the Faculty of Nursing at Mansoura University 
and the certificate ethical number was 182. As well, formal acceptance was obtained from the hospital's administrative authority. Informed consent was obtained from the patients' families (next of kin), who were informed about the study, including the aim, procedure, benefits, and risks. The voluntary nature of participation and the right to withdraw at any time without responsibility were also emphasized to them.
Furthermore, the confidentiality of the participants' personal information was maintained.

\subsection{Data collection procedure}

The present study was conducted in three phases: preparation, implementation, and evaluation. The data were collected between June 2019 and August 2020 (see Figure 1).

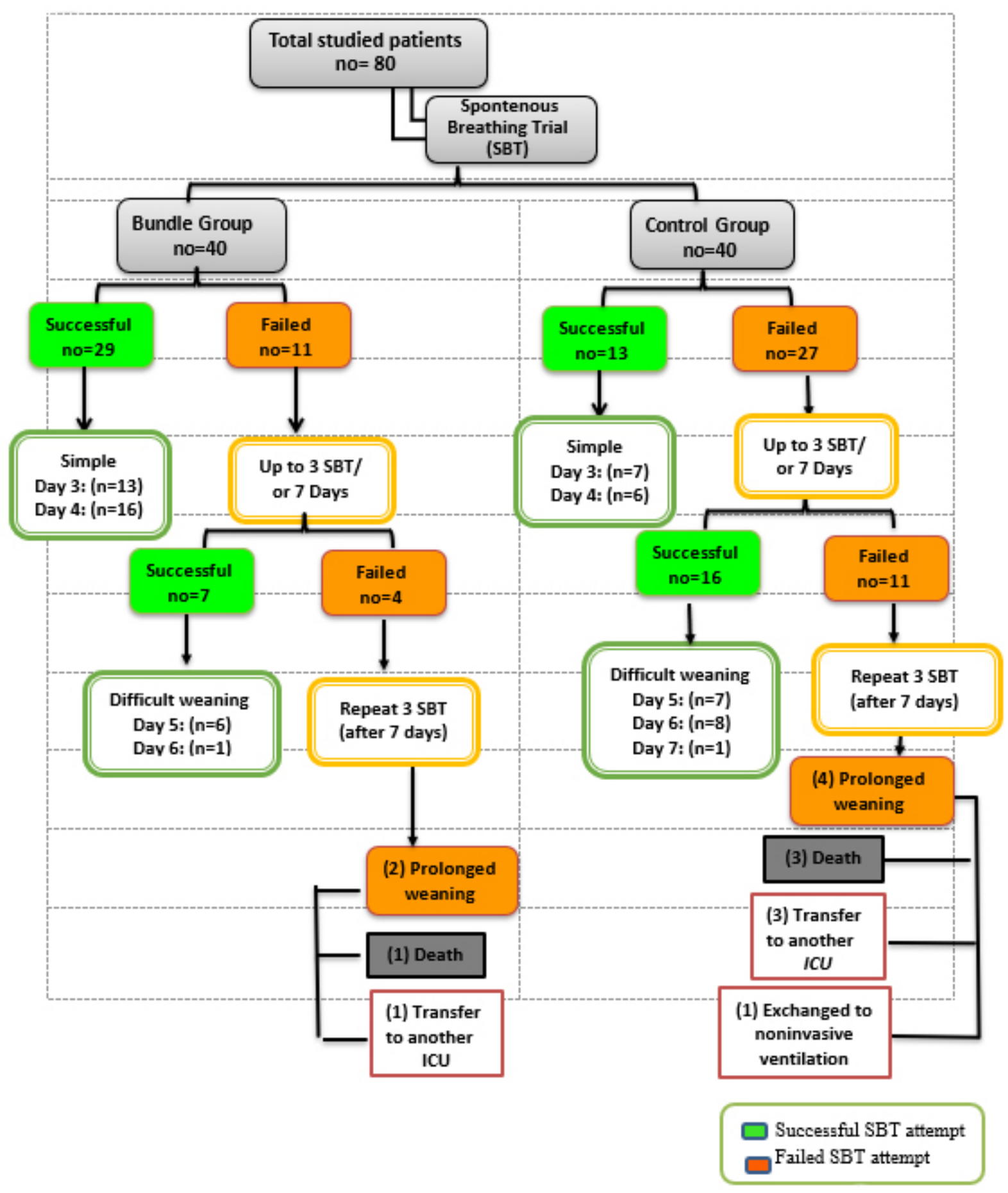

Figure 1. Weaning outcome flowchart among studied patients according to SBT 


\subsubsection{Preparation phase}

This phase involved preparing data collection tools and obtaining ethical approval and the hospital's permission to conduct the study. This phase was completed in 2 months (June and July 2019).

\subsubsection{Implementation phase}

(1) This phase was conducted for 13 months, from August 2019 to August 2020. The PR initiated the data collection by visiting the study settings. All patients admitted to the respiratory ICUs were screened daily to identify COPD patients who were experiencing acute exacerbation and requiring endotracheal intubation and IMV for study inclusion. The PR started data collection from the control group. The patients' baseline and health-relevant data were collected using tool I. These data were obtained from the patients' medical records, family, and health team personnel.

(2) Patients in the control group received routine ICU care. The routine ICU care included most of the items of VCB but not in a usual and regular manner as elevating the head of the bed between $30 \%$ and $45 \%$, sedation interruption, and administering deep venous thrombosis and peptic ulcer drugs. Routine care also involved performing patient hygiene, giving enteral nutrition, monitoring patients, and administering drugs. Furthermore, the physician assessed the patients' readiness for weaning after 48-72 hrs. of IMV.

(3) After finishing the data collection from the control group, the PR educated the CCNs about the significant impact of implementing the VCB for mechanically ventilated patients. Patients in the bundle group received evidence-based VCB practices by the medical and nursing staff's cooperation using tool II. The VCB practices include the following:

- Elevating the head of the bed to approximately $30^{\circ}-45^{\circ}$ and ensuring that tubes and attachments are properly placed to prevent accidental removal.

- Oral care comprises oral cavity assessment for any inflammation, gentle brushing of the patient's teeth, gums, tongue, and hard palate using $2 \%$ Chlorhexidine three times per day (once every $8 \mathrm{hrs}$.), and application of a water-based moisturizer to maintain oral mucosa integrity.

- Tracheal suctioning using the open suction system technique was performed only when indicated (avoid routine suction), including prior pulmonary auscultation and avoiding instillation of $0.9 \%$ saline or any other solution type. Care related to suctioning included putting the patient in the semi-Fowler's position, wearing sterile gloves, preoxygenating the patient before suctioning, and limiting the suction time to no more than 10 seconds. Care also included reoxygenating after suctioning and continuous monitoring of the patient's vital signs for at least 10 minutes following suctioning because hypercapnia tends to increase during this period.

- Daily sedation interruption and assessing patient's sedation level using RASS.

- Daily assessment of readiness to wean was done for each eligible patient by the PR and the qualified nurses after 24 hrs. of IMV initiation using the BWAP checklist. it was kept in the patient's file as a daily monitoring tool until the COPD patients were weaned from IMV using tool III part one. Whenever the patient had BWAP score $\geq 65 \%$ (17 or above from checklist), the PR and qualified nurses informed the responsible respiratory therapist about the patient's readiness for weaning. Consequently, the weaning process was initiated.

- Deep venous thrombosis prophylaxis was administered following the physician's order and the nurse applied the elastic stocking on the patient's leg.

- Early mobilization was typically performed within 24-48 hrs. of ICU admission, which included active/passive range of motion exercise and changing the patient's position every 2 hrs.

- Peptic ulcer prophylaxis was administered following the physician's order, the gastric residual volume was checked before each feed, and intermittent rather than continuous enteral feeding was administered.

- Finally, each eligible patient received specific practices related to infection control measures including performing hand hygiene, wearing sterile gloves, applying patient's hygiene, and administering the prescribed drugs.

- Ventilator care bundle compliance was monitored daily by an assigned staff member to ensure that the VCB elements were competently applied. The assigned staff were selected based on their competency, dedication to direct patient care, ICU availability, and willingness to participate in the study.

\subsubsection{Evaluation phase}

(1) In this phase, The BWAP checklist was used after 24 hrs. of ICU admission to assess the patient's readiness for weaning. The assessment was conducted in the morning and afternoon shifts because patients needed to relax during night shifts. Moreover, the weaning process was usually started during the day.

(2) The spontaneous breathing trial (SBT) was implemented for all eligible patients in both groups started on day 3 of the study. Moreover, the SBT was repeated in the following days 
if the patient was again ready to wean.

(3) The weaning process outcome was investigated during the SBT as follows:

- Simple: successful SBT on the first attempt.

- Difficult: failed SBT on the first attempt and required up to three trials or seven days to complete a successful SBT.

- Prolonged: required more than 7 days to complete a successful SBT.

(4) The ventilation duration and the length of ICU stay were evaluated after completing the weaning process for each patient using part 2 of tool III.

\subsection{Statistical analysis}

The obtained data were coded, computed, and statistically analyzed using the Statistical Package for the Social Sciences (Chicago, IL, USA), version 20. All continuous data were normally distributed and were expressed in mean \pm standard deviation $(S D)$. Categorical data were expressed in numbers and percentages. Student's $t$-test and chi-square $\left(\chi^{2}\right)$ test were used to compare continuous quantitative (two groups) and categorical variables, respectively. The statistical significance level was set at $p<.05$.

Table 1. Health relevant data of the studied groups during ICU admission

\begin{tabular}{|c|c|c|c|c|}
\hline \multirow{2}{*}{ Variables } & \multirow{2}{*}{$\begin{array}{l}\text { Bundle Group }(\mathrm{n}=40) \\
\text { Mean } \pm S D\end{array}$} & \multirow{2}{*}{$\begin{array}{l}\text { Control Group }(\mathrm{n}=40) \\
\text { Mean } \pm \text { SD }\end{array}$} & \multicolumn{2}{|c|}{ Significant test } \\
\hline & & & $t$ & $p$-value \\
\hline Glasgow Coma Scale value & $11.8 \pm 2.0$ & $11.5 \pm 1.8$ & 0.585 & .560 \\
\hline \multicolumn{5}{|l|}{ Hemodynamic data } \\
\hline SBP (mmHg) & $116.8 \pm 9.7$ & $115.4 \pm 14.8$ & 0.491 & .625 \\
\hline $\mathrm{DBP}(\mathrm{mmHg})$ & $75.5 \pm 6.8$ & $73.0 \pm 8.8$ & 1.421 & .159 \\
\hline Heart rate & $99.4 \pm 13.1$ & $97.6 \pm 11.9$ & 0.636 & .527 \\
\hline $\mathrm{CVP}(\mathrm{mmHg})$ & $8.1 \pm 1.2$ & $7.4 \pm 1.9$ & 1.923 & .109 \\
\hline Temperature $\left({ }^{\circ} \mathrm{C}\right)$ & $36.7 \pm 0.3$ & $36.8 \pm 0.3$ & 1.491 & .272 \\
\hline \multicolumn{5}{|l|}{ Arterial blood gases } \\
\hline $\mathrm{Ph}$ & $7.1 \pm 0.3$ & $7.2 \pm 0.3$ & 1.491 & .272 \\
\hline $\mathrm{PaO}_{2}(\mathrm{mmHg})$ & $60.2 \pm 3.3$ & $60.9 \pm 4.6$ & 0.776 & .440 \\
\hline $\mathrm{PaCO}_{2}(\mathrm{mmHg})$ & $72.6 \pm 12.4$ & $70.0 \pm 17.9$ & 0.763 & .448 \\
\hline $\mathrm{HCO}_{3}(\mathrm{mEq} / \mathrm{L})$ & $27.5 \pm 5.1$ & $25.7 \pm 5.5$ & 1.477 & .144 \\
\hline $\mathrm{PaO}_{2} / \mathrm{FiO}_{2}$ & $130.5 \pm 43.8$ & $134.1 \pm 57.5$ & 0.315 & .729 \\
\hline \multicolumn{5}{|l|}{ Ventilator parameters } \\
\hline $\mathrm{FiO}_{2}$ & $0.42 \pm 0.09$ & $0.46 \pm 0.1$ & 1.880 & .120 \\
\hline Set RR (b/pm) & $16.1 \pm 2.9$ & $14.9 \pm 2.8$ & 1.883 & .119 \\
\hline $\mathrm{Vt}(\mathrm{ml} / \mathrm{Kg})$ & $362.3 \pm 74.9$ & $343.9 \pm 67.0$ & 1.158 & .250 \\
\hline VE (liter) & $6.79 \pm 0.8$ & $6.81 \pm 0.8$ & 0.113 & .911 \\
\hline I:E ratio & $0.308 \pm 0.006$ & $0.310 \pm 0.038$ & 0.244 & .808 \\
\hline $\operatorname{PEEP}\left(\mathrm{cm} \mathrm{H}_{2} \mathrm{O}\right)$ & $5.1 \pm 0.7$ & $5.3 \pm 0.9$ & 1.109 & .535 \\
\hline Variables & n (\%) & n $(\%)$ & $\chi^{2}$ & $p$-value \\
\hline \multicolumn{5}{|l|}{ Comorbidity } \\
\hline No & $4(10.0 \%)$ & $5(12.5 \%)$ & \multirow{2}{*}{0.125} & \multirow{2}{*}{.723} \\
\hline Yes & $36(90.0 \%)$ & $35(87.5 \%)$ & & \\
\hline \multicolumn{5}{|l|}{ Type of co-morbidity } \\
\hline Diabetes mellitus & $20(55.6 \%)$ & $25(71.4 \%)$ & 1.926 & .165 \\
\hline Hypertension & $18(50.0 \%)$ & $18(51.4 \%)$ & 0.014 & .904 \\
\hline Ischemic heart disease & $9(25.0 \%)$ & $5(14.3 \%)$ & 1.287 & .257 \\
\hline Acute kidney injury & $6(16.7 \%)$ & $8(22.9 \%)$ & 0.430 & .512 \\
\hline Hepatic impairment & $2(5.6 \%)$ & $6(17.1 \%)$ & 2.383 & .123 \\
\hline Mitral stenosis & $3(8.3 \%)$ & $0(0.0 \%)$ & 3.045 & .081 \\
\hline Atrial fibrillation & $2(5.6 \%)$ & $0(0.0 \%)$ & 2.001 & .157 \\
\hline \multicolumn{5}{|l|}{ Sedation administration } \\
\hline Yes & $40(100 \%)$ & $40(100 \%)$ & \multirow{2}{*}{0} & \multirow{2}{*}{1.000} \\
\hline No & $0(0.0 \%)$ & $0(0.0 \%)$ & & \\
\hline
\end{tabular}

Note. DBP: Diastolic Blood Pressure; Hb: Hemoglobin; PEEP: Positive End Expiratory Pressure; PaCO 2 : Arterial Carbon Dioxide Tension; SBP: Systolic Blood Pressure; CVP: Central Venous Pressure; RR: Respiratory Rate; Vt: Tidal Volume; IE: Inspiration to Expiration Ratio; $\mathrm{PaO}_{2}$ : Arterial Oxygen Tension; FiO ${ }_{2}$ : Fraction of Inspired Oxygen; $\mathrm{HCO}_{3}$ : Serum Bicarbonate; $\mathrm{FiO}_{2}$, Fraction of Inspired Oxygen; $p>.05$ : Statistically insignificant; $\chi^{2}$ : Chi-square test; $t$ : Student t-test; VE: Minute Volume 


\section{Results}

Regarding the patients' socio-demographic characteristics, it was observed that more than half of the studied patients in both groups were between 56 and 65 years old (bundle group, $52.5 \%$ \& control group, $55.0 \%$ ). The study sample was predominantly males, which constituted $77.5 \%$ of the bundle group and $72.5 \%$ of the control group. Concerning the smoking habits, nearly two-thirds of the bundle group $(65.0 \%)$ were ex-smokers compared with $47.5 \%$ of the control group. No statistically significant differences were found between both groups regarding the socio-demographic characteristics, which indicates the similarity of both groups before intervention (data not tabulated).

Table 1 illustrates the health profile data of the studied groups during ICU admission. No statistically significant differences were noticed between the study groups regarding healthrelevant data, which indicates similarity in both groups. The results demonstrated that the average score of the Glasgow
Coma Scale (GCS) was $11.8 \pm 2.0$ in the bundle group and $11.5 \pm 1.8$ in the control group. All hemodynamic parameters matched in both groups before intubation and the baseline characteristics of the ventilator parameters were comparable. Additionally, all parameters of the arterial blood gases (ABGs) deteriorated on admission. Furthermore, the commonest comorbidities among the studied patients were diabetes mellitus (DM) and hypertension (the bundle group: $55.6 \% \& 50.0 \%$ and the control group: $71.4 \% \& 51.4 \%$ respectively). The results showed that all the studied patients $(100 \%)$ required sedation administration during intubation.

Table 2 describes the percentage of daily RASS assessments throughout the study period between the study groups. It showed that the frequency of ideal RASS scores ( -2 to 1$)$ in the bundle group is substantially more than the control group. Furthermore, statistically significant differences were noted only between both groups on the fourth day of the study ( $p=$ $.013)$.

Table 2. Daily Richmond Agitation Sedation Scale assessment throughout the study period between studied groups

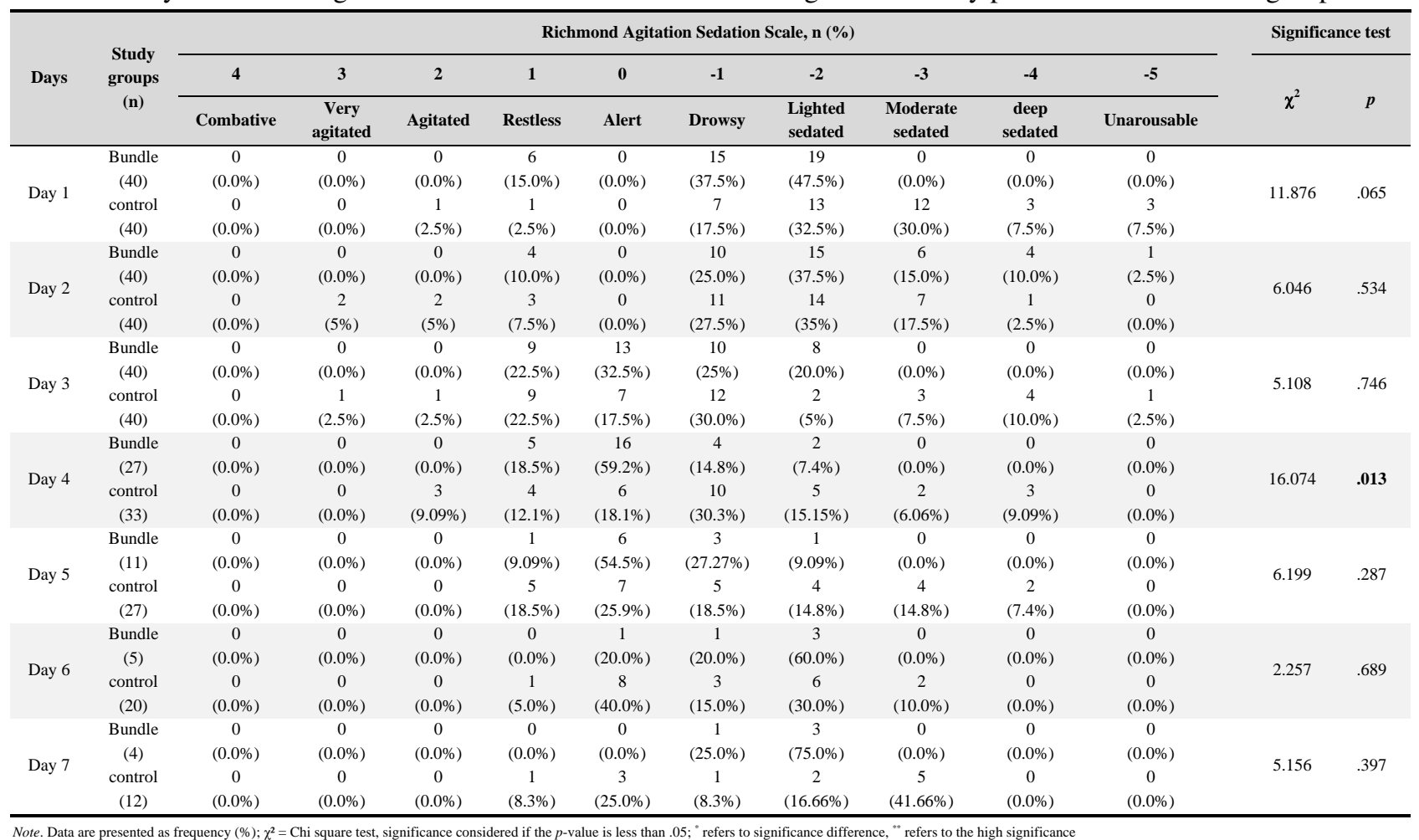

Table 3 presents the frequency of the BWAP ideal scores between the studied groups. The BWAP score was not calculated for any of the studied patients on day 1 of the study. Moreover, the results demonstrated that no patients in either group obtained a BWAP score $\geq 65 \%$ on day 2 of the study. However, the findings on day 3 showed that $32.5 \%$ of the bundle group had a BWAP score of $\geq 65 \%$ in comparison with only $17.5 \%$ in the control group. After day 3 of the study, the number of patients in both groups continuously decreased daily because of patients' weaning from MV, recovery, sudden discharge/transfer, or death. On day 4 of the study period, the findings illustrated that $59.3 \%$ of the 27 pa- 
tients in the bundle group became weanable compared with $18.2 \%$ of the 33 patients in the control group. Similarly, on day 5 of the study, more than half $(54.5 \%)$ of the 11 patients in the bundle group had a BWAP score of $\geq 65 \%$ in comparison with $25.9 \%$ of the 27 patients in the control group. On day 6 of the study, the remaining patients of both groups had a BWAP score $\geq 65 \%$ as follows: $20.0 \%$ out of 5 patients of the bundle group and $40.0 \%$ out of 20 patients of the control group. No patients obtained a BWAP score of $\geq 65$ among the remaining patients in the bundle group on the last day of the study. However, one $(8.3 \%)$ of the 12 patients in the control group had a BWAP score of $\geq 65 \%$. On day four of the study period, highly statistically significant differences were noted between both groups regarding the BWAP scores $(p<.001)$.

Table 4 compares the patients' outcomes between the studied groups. Highly statistically significant differences were noted between both groups regarding the weaning outcome, the ventilation duration, and the length of ICU stay $(p<$ .001). Almost three-quarters of the bundle group were noted to simply be weaned from IMV in comparison with $32.5 \%$ of the control group. Additionally, the ventilation duration and the length of ICU stay were reduced in the bundle group compared to the control group.

Table 3. Comparing Burn's Weaning Assessment Program score between the studied groups during ventilation days

\begin{tabular}{|c|c|c|c|c|c|c|c|c|}
\hline \multirow{3}{*}{$\begin{array}{c}\text { Ventilation } \\
\text { days }\end{array}$} & \multicolumn{6}{|c|}{ BWAP score } & \multirow{2}{*}{\multicolumn{2}{|c|}{ Significance test }} \\
\hline & \multicolumn{3}{|c|}{ Bundle group } & \multicolumn{3}{|c|}{ Control group } & & \\
\hline & Patient no. & $<65 \%, \mathrm{n}(\%)$ & $\geq 65 \%, n(\%)$ & Patient no. & $<65 \%, \mathrm{n}(\%)$ & $\geq 65 \%, n(\%)$ & $\chi^{2}$ & $p$ \\
\hline Day 2 & 40 & $40(100 \%)$ & $0(0.0 \%)$ & 40 & $40(100 \%)$ & $0(0.0 \%)$ & 0 & 1.000 \\
\hline Day 3 & 40 & $27(67.5 \%)$ & $13(32.5 \%)$ & 40 & $33(82.5 \%)$ & $7(17.5 \%)$ & 2.400 & .121 \\
\hline Day 4 & 27 & $11(40.7 \%)$ & $16(59.3 \%)$ & 33 & $27(81.8 \%)$ & $6(18.2 \%)$ & 10.79 & $<.001^{* *}$ \\
\hline Day 5 & 11 & $5(45.5 \%)$ & $6(54.5 \%)$ & 27 & $20(74.1 \%)$ & $7(25.9 \%)$ & 2.844 & .092 \\
\hline Day 6 & 5 & $4(80.0 \%)$ & $1(20.0 \%)$ & 20 & $12(60.0 \%)$ & $8(40.0 \%)$ & 0.694 & .405 \\
\hline Day 7 & 4 & $4(100 \%)$ & $0(0.0 \%)$ & 12 & $11(91.7 \%)$ & $1(8.3 \%)$ & 0.356 & .551 \\
\hline
\end{tabular}

Note. Data are presented as frequency $(\%) ; \chi^{2}=$ chi-square test, significance considered if the $p$-value is less than $.05 ;{ }^{*}$ significance difference, ${ }^{* *}$ high significance; BWAP: Burn's Weaning Assessment Program; VCB: Ventilator Care Bundle; BWAP score of $\geq 65 \%$ : weaning probably; BWAP score of < 65\%: weaning improbable

Table 4. Comparison between patients' outcomes in the studied groups

\begin{tabular}{|c|c|c|c|c|c|}
\hline \multirow{2}{*}{\multicolumn{2}{|c|}{ Patients' outcome }} & \multirow{2}{*}{$\begin{array}{l}\text { Bundle Group } \\
(\mathrm{n}=\mathbf{4 0})\end{array}$} & \multirow{2}{*}{$\begin{array}{l}\text { Control Group } \\
(\mathrm{n}=40)\end{array}$} & \multicolumn{2}{|c|}{ Significance test } \\
\hline & & & & $\chi^{2}$ & $p$ \\
\hline \multicolumn{6}{|c|}{ Weaning outcome, n (\%) } \\
\hline \multicolumn{2}{|c|}{ Success (simple) } & $29(72.5 \%)$ & $13(32.5 \%)$ & 14.532 & $<.001^{* *}$ \\
\hline \multicolumn{2}{|c|}{ Failure } & $11(27.5 \%)$ & $27(67.5 \%)$ & 0.063 & .802 \\
\hline ○ & Difficult & $7(17.5 \%)$ & $16(40.0 \%)$ & & \\
\hline ○ & Prolonged & $2(5.0 \%)$ & $4(10.0 \%)$ & & \\
\hline & Others & $2(5.0 \%)$ & $7(17.5 \%)$ & & \\
\hline \multicolumn{2}{|c|}{ Ventilation duration, mean $\pm S D$} & $4.1 \pm 1.8$ & $6.3 \pm 2.2$ & 4.895 & $<.001^{* *}$ \\
\hline \multicolumn{2}{|c|}{ Length of ICU stay (days), mean $\pm S D$} & $6.2 \pm 3.0$ & $9.8 \pm 4.2$ & 4.411 & $<.001^{* *}$ \\
\hline
\end{tabular}

Note. ICU: Intensive Care Unit; SD: Slandered Deviation; Others include that the patient is (un-weanable, death, transfer to another ICU, exchanged to noninvasive ventilation; Data are presented as frequency (\%), $p$ by chi-Square test (Monte Carlo Exact Probability); Significance is considered if the $p$-value is less than $.05,{ }^{* *}$ high significance

\section{DISCUSSION}

Previous studies had demonstrated the positive impact of the VCB in reducing the incidence of VAP. ${ }^{[25-28]}$ Our study focused on investigating the effect of implementing VCB on the early weaning of patients with COPD in Egypt.

\subsection{Health relevant data of studied patients}

On admission, the current findings illustrated that most of the studied patients were semiconscious in both groups. Based on a recent literature review, the change in the mental status or altered level of consciousness among COPD patients is 
considered as one of the important indications for IMV initiation. ${ }^{[5]}$ These findings are congruent with Mohamed et al. ${ }^{[38]}$ who found that the mean GCS score among COPD patients necessitating IMV was $10.73 \pm 1.49$. Another prospective observational study discovered that the mean GCS score among the noninvasive ventilation failure group was 11.421 \pm 0.902 . $^{[39]}$

Regarding hemodynamic and ventilator parameters, the current findings documented that no statistically significant differences were detected between both groups during respiratory ICU admission. Our results are aligned with the results of Khalil, Abd Elfattah, and El-Qusy ${ }^{[40]}$ which revealed that the patients' hemodynamic parameters pre-intubation were matched with no statistically significant differences between the studied groups. Similarly, Nafae et al. ${ }^{[41]}$ found no statistically significant difference $(p>.05)$ between the participant groups regarding ventilator parameters $(\mathrm{FiO} 2$, tidal volume, respiratory rate, pressure support, and PEEP).

On admission, all ABG parameters in COPD patients who required ventilatory support had deteriorated. According to the literature, hypercapnia is a mutually significant complication in COPD patients, leading to severe respiratory acidosis. ${ }^{[42]}$ In addition, one of the most common reasons for ICU admission and IMV initiation among COPD patients is severe respiratory acidosis despite supplementary oxygen. ${ }^{[43]}$ This finding is similar to the results of other studies $\left(.^{[40,41]}\right.$

Regarding previous medical history, DM and hypertension (HTN) were the most common comorbidities in the studied sample. Based on the recent literature review, this may be due to the high prevalence of type 2 DM and HTN in Egypt. According to the International Diabetic Federation (IDF), Egypt is the ninth country worldwide burdened with higher prevalence rates (8.9 million), which is expected to increase by 15 million in $2045 .^{[44]}$ Furthermore, it was estimated that 1.28 billion people worldwide have hypertension, with most (two-thirds) living in low- and middle-income countries. ${ }^{[45]}$

According to Mahishale et al., ${ }^{[46]}$ COPD is associated with important chronic comorbidities including DM and HTN. They also found that the prevalence of DM and HTN were present in $25.94 \%$ and $37.25 \%$ of the 2432 COPD patients, respectively. Additionally, some studies reported a strong association between diabetes mellites and COPD that affect patients' prognosis. ${ }^{[4-49]}$

By assessing the patients' sedation level, our findings showed that the frequency of ideal RASS scores (-2 to 1 ) in the bundle group is substantially higher than in the control group. As well, statistically significant differences were noted between both groups on the fourth day of the study $(p=.013)$.
These findings can be explained by conducting patients' assessments before withholding the sedative agent, holding the tranquilizing drug in the early morning, and continuously monitoring sedation levels using RASS as a part of the VCB nursing training sessions with patients in the study group. As well, effective pain control and better sedation assessment using RASS scoring systems result in reducing delirium and ventilation duration among MVPs $^{[50]}$ and improving the level of consciousness. ${ }^{[51]}$

This finding is in harmony with the results of several studies which highlighted that nurses utilizing RASS limit the over-sedation of ventilated patients, thereby reducing the number of MV days in the ICU. ${ }^{[52-54]}$ Furthermore, Klompas et al. ${ }^{[5]}$ reported that sedative infusion interruptions were associated with faster extubation time and lower rates of ventilator mortality.

On the other hand, Yilmaz et al. ${ }^{[56]}$ reported that a physicianled daily sedation vacation compared to a sedation protocol led by a nurse reduced the ventilation duration significantly. This discrepancy could be attributed to nurses' lack of knowledge and skills in assessing their patients' sedation levels. In addition, the participant nurses' performance of sedation assessment using the RASS in the current study were competent after educational training, which affected the patients' outcome.

\subsection{Effect of implementing a VCB on COPD patients' weaning outcomes}

The findings of the present study showed that the use of the BWAP checklist can correctly predict the patients' successful weaning from IMV. Additionally, the majority of the bundle group had a better BWAP score $(\geq 65 \%)$ when compared with the control group. This can be attributed to the fact that the BWAP checklist involved several parameters that can predict factors affecting patients' weaning outcomes. ${ }^{[16]}$ Indeed, early detection and correction of any abnormalities in these parameters can enhance the liberation from ventilatory support earlier with better patient outcomes.

This is compatible with a cross-sectional study conducted by Keykha et al. ${ }^{[35]}$ who reported that the BWAP checklist was a precise tool for successfully predicting the weaning from MV. Furthermore, Jeong and Lee ${ }^{[57]}$ demonstrated that the study group has a significantly increased rate of successful weaning scores post-application of the BWAP checklist when compared with the control group. In addition, Yazdannik et al. ${ }^{[16]}$ reported that using BWAP by nurses to determine patients' readiness for weaning off the ventilator is a safe manner during the day and reduces the length of ventilatory support when compared to routine methods. 
The findings of this study illustrated that almost threequarters of the bundle group was simply weaned from IMV in comparison with one-third of the control group with a highly statistically significant difference $(p<.001)$. This finding is related to the use of competent VCB practices that significantly reduced the incidence of ventilator-associated complications ${ }^{[24,25]}$ and improved the patients' outcomes. ${ }^{[32,58]}$

Accordingly, VCB implementation ensures that all patients on IMV receive standard therapies to prevent frequent complications that delay weaning such as gastrointestinal bleeding $^{[32]}$ and VAP. ${ }^{[27,28]}$ Equally, it provides an opportunity for the daily assessment of the patient's readiness for weaning and the discontinuation of IMV as early as possible. ${ }^{[36]}$

The results of the present study agreed with a recent work done by Eweas et al. ${ }^{[59]}$ who noticed that the intervention group obtained a higher weaning score than the control group with statistically significant differences between both groups regarding the fourth BWAP observation $(p>.05)$. Similarly, El-Sharkawy, Mohamed, and $\mathrm{Ali}^{\left[{ }^{[0]}\right]}$ investigated the effect of VCB implementation on weaning indicators among MVPs and found that the study group who received complete VCB practices obtained higher weaning scores than the control group.

\subsection{Effect of implementing a VCB on COPD patients' ventilation duration and length of ICU stay}

The present study showed a significantly shorter ventilation duration ( $4.1 \pm 1.8$ days) in the bundle group than in the control group ( $6.3 \pm 2.2$ days). These findings are supported by other similar studies. Eweas et al. ${ }^{[59]}$ illustrated that more than two-thirds of the study group had a shorter MV (4-6 days) duration following VCB implementation when compared with only two-fifth of the control group.

Moreover, Khalil et al. ${ }^{[36]}$ reported that most of the intervention group has obtained a shorter length of IMV (3-6 days) than the control group (7-12 days) after implementation of the bundle with a statistically significant difference between the two groups. In the same sense, Montasser ${ }^{[37]}$ revealed a significant statistical difference between cases with complete and incomplete ventilator bundle implementation groups regarding IMV connection duration.

Concerning the length of ICU stay, there was a significantly shorter length of ICU stay among the study group. The median length of ICU stay in the bundle group was $6.2 \pm 3.0$ days versus $9.8 \pm 4.2$ days in the control group. This may be attributed to the positive effect of the VCB nursing training sessions on the outcomes of MVPs. This will subsequently decrease the costs of treatments. These findings are harmonious with Samra, Sherif, and Elokda ${ }^{[61]}$ who investigated the impact of VAP bundle adherence among MVPs and its effectiveness in adult ICU. They declared that the intervention group has a lower length of ICU stay than the control group.

Additionally, Karagozoglu et al. ${ }^{[62]}$ noticed that the length of hospital stays on IMV is statically shorter in the control than in the uncontrolled group. Furthermore, several studies showed that the implementation of a VCB and staff education has decreased both ventilator-associated complications and length of ICU stay among studied patients. ${ }^{[63,64]}$

\section{Conclusions}

Based on the study findings, it can be concluded that the implementation of the VCB improves COPD patients' outcomes. The COPD patients who received the VCB had higher weaning scores, shorter ventilation duration, and decreased ICU length of stays compared to the control group who received routine ICU care. Hence, we recommend the integration of the VCB into the daily care of MVPs, as this may enhance the simple weaning, and reduce the duration of mechanical ventilation and the ICU length of stay.

\subsection{Limitations of the study}

This study has two limitations. First, the study was conducted in two respiratory ICUs at a selected hospital. Second, the study involved a relatively small group of COPD patients (80 patients). These two factors limit the generalizability of the research findings.

\subsection{Recommendation}

Based upon the findings of the present study, the following suggestions can be recommended:

(1) For nurses:

- A continuous periodical training program for CCNs to develop their knowledge, and performance in caring for MVPs.

- Critical care nurses should integrate the VCB practices into their daily practice to improve the quality of care and achieve a good patient outcome.

- Strict supervision and follow-up of nurses' adherence to $\mathrm{VCB}$ practices with their patients.

(2) For patients:

- Assessing the effectiveness of VCB on VAP occurrence, hospital costs, and extubation outcome.

- Assessing factors affecting the weaning outcome among MVPs.

- Assessing variables that predict the weaning outcome among MVPs. 


\section{ACKNOWLEDGEMENTS}

Special thanks and appreciation go to my supervisors for their support, valuable instruction, and prompt assistance. I would also like to extend my deep thanks to physicians, nurses, patients who accepted to take a part in this study. and to all those who directly or indirectly helped me to accomplish this thesis.

\section{CONFlicts of InTEREST Disclosure}

The authors declare they have no conflicts of interest.

\section{REFERENCES}

[1] De Haro C, Ochagavia A, López-Aguilar J, et al. Patient-ventilator asynchronies during mechanical ventilation: current knowledge and research priorities. Intensive Care Medicine Experimental. 2019; 7(1): 1-14. PMid: 31346799. https://doi.org/10.1186/s406 35-019-0234-5

[2] Demoule A, Brochard L, Dres M, et al. How to ventilate obstructive and asthmatic patients. Intensive Care Medicine. 2020; 46(12): 24362449. PMid: 33169215. https://doi.org/10.1007/s00134-0 20-06291-0

[3] Talwar D, Dogra V. Weaning from mechanical ventilation in chronic obstructive pulmonary disease: Keys to success. The Journal of Association of Chest Physicians. 2016; 4(2): 43. https://doi.org/ 10.4103/2320-8775.183839

[4] Brown H, Dodic S, Goh SS, et al. Factors associated with hospital mortality in critically ill patients with exacerbation of COPD. International Journal of Chronic Obstructive Pulmonary Disease. 2018; 13: 2361. PMid: 30122916. https://doi.org/10.2147/COPD.S 168983

[5] Global Strategy for the Diagnosis, Management and Prevention of COPD, Global Initiative for Chronic Obstructive Lung Disease (GOLD). 2020 [Accessed 19 April 2020]. Available from: http://goldcopd.org/

[6] World Health Organization. The top 10 causes of death. 9 December 2020. Available from: https://www . who.int/news-room/fact - sheets/detail/the-top-10-causes-of-death

[7] Ahmed SM, Athar M. Mechanical ventilation in patients with chronic obstructive pulmonary disease and bronchial asthma. Indian journal of Anaesthesia. 2015; 59(9): 589. PMid: 26556918. https://doi.org/10.4103/0019-5049.165856

[8] Song Y, Chen R, Zhan Q, et al. The optimum timing to wean invasive ventilation for patients with AECOPD or COPD with pulmonary infection. International Journal of Chronic Obstructive Pulmonary Disease. 2016; 11: 535. PMid: 27042042. https ://doi.org/10 .2147/COPD. S96541

[9] Haribhai S, Mahboobi SK. Ventilator Complications. StatPearls [Internet]. 2021.

[10] Wu D, Wu C, Zhang S, et al. Risk factors of ventilator-associated pneumonia in critically III patients. Frontiers in Pharmacology. 2019; 10: 482. PMid: 31143118. https://doi.org/10.3389/fphar. 2019.00482

[11] Markle AG. Common complications of mechanical ventilation and multimodal prevention strategies (Doctoral dissertation, University of Zagreb. School of Medicine. Department of Anaesthesiology, Resuscitation and Intensive Care in Surgical Specialities). 2014. Aailable from: https://urn.nsk.hr/urn:nbn:hr:105:931105

[12] Zhang C, Zhang Z, Mi J, et al. The cumulative venous thromboembolism incidence and risk factors in intensive care patients receiving the guideline-recommended thromboprophylaxis. Medicine. 2019; 98(23). PMid: 31169685. https://doi.org/10.1097/MD.000 0000000015833

Published by Sciedu Press
[13] Goldsmith JP, Karotkin E, Suresh G, et al. Assisted ventilation of the neonate E-book. Elsevier Health Sciences; 2016.

[14] Vetrugno L, Guadagnin GM, Brussa A, et al. Mechanical ventilation weaning issues can be counted on the fingers of just one hand: part 1. The Ultrasound Journal. 2020; 12(1): 1-10. PMid: 32166566. https://doi.org/10.1186/s13089-020-00161-y

[15] Demoule A, Brochard L, Dres M, et al. How to ventilate obstructive and asthmatic patients. Intensive Care Medicine. 2020; 46(12): 2436 2449. PMid: 33169215. https ://doi .org/10.1007/s00134-0 20-06291-0

[16] Yazdannik A, Salmani F, Irajpour A, et al. Application of Burn's wean assessment program on the duration of mechanical ventilation among patients in intensive care units: A clinical trial. Iranian Journal of Nursing and Midwifery Research. 2012; 17(7): 520.

[17] Institute for Health Care Improvement. How-to guide: Prevent ventilator-associated pneumonia. Cambridge. MA: Institute for Healthcare Improvement; 2012. Available from: http://www.ihi.org/resources/Pages/Tools/HowtoGui dePreventVAPPediatricSupplement.aspx

[18] Osti C, Wosti D, Pandey B, et al. Ventilator-Associated Pneumonia and Role of Nurses in Its Prevention. Journal of the Nepal Medical Association. 2017; 56(208). https://doi.org/10.31729/jnma. 3270

[19] Boltey E, Yakusheva O, Costa DK. 5 Nursing strategies to prevent ventilator-associated pneumonia. American Nurse Today. 2017; 12(6): 42.

[20] Dumbre DU. A Study to Assess the Knowledge and Compliance of Critical Care Nurses Regarding Ventilator Care Bundle in Prevention of Ventilator Associated Pneumonia. Medico-legal Update. 2019; 19(1): 176-178. https://doi.org/10.5958/0974-1283. 2019 .00035 .5

[21] Sayed SS, Ahmed KH, Kinawy SA, et al. Clinical outcome of wean ing in mechanically ventilated patients with chronic obstructive pulmonary disease. Egyptian Journal of Bronchology. 2019; 13(4): 484 488. https://doi.org/10.4103/ejb.ejb_9_19

[22] Farouk MH, Elhawary A, Shouman W, et al. Assessment of Weaning Practice In Mechanically Ventilated Chronic Obstructive Pulmonary Disease Patients at Respiratory Intensive Care Unit of Zagazig University Hospitals. Zagazig University Medical Journal. 2020; 26(5): 883-891.

[23] Loss SH, Oliveira RP, Maccari JG, et al. The reality of patients requiring prolonged mechanical ventilation: a multicenter study. Revista Brasileira de terapia intensive. 2015; 27: 26-35. PMid: 25909310 . https://doi.org/10.5935/0103-507X.20150006

[24] Alcan AO, Korkmaz FD, Uyar M. Prevention of ventilator-associated pneumonia: Use of the care bundle approach. American Journal of Infection Control. 2016; 44(10): e173-e176. PMid: 27388264 https://doi.org/10.1016/j.ajic.2016.04.237

[25] Alsoda MF, Al-Shahat MM, Reda SMK, et al. Implementation of ventilator bundle for prevention of ventilator-associated pneumonia 
in pediatric intensive care unit. Journal of Medicine in Scientific Research. 2019; 2(4): 265.

[26] Liu W, Yang Y, Jiao Y, et al. Evaluation of the effects of applying the ventricular care bundle (VCB) method for reducing ventilatorassociated pneumonia (VAP) in the intensive care unit of a general Chinese tertiary hospital. Ann Palliat Med. 2020; 9: 2853-61. PMid: 32787352. https://doi.org/10.21037/apm-20-289

[27] Mogyoródi B, Dunai E, Gál J, et al. Ventilator-associated pneumonia and the importance of education of ICU nurses on preventionPreliminary results. Interventional Medicine and Applied Science. 2016; 8(4): 147-151. PMid: 28180003. https://doi.org/10.1 $556 / 1646.8 .2016 .4 .9$

[28] Santos ECW, Barilli S, Zigiotto C, et al. Efficacy of a Bundle for Prevention of Ventilator Associated Pneumonia in an Adult Intensive Care Unit. European Respiratory Journal. 2020. https : //doi.org/10.1183/13993003. congress-2020.2021

[29] Polit DF, Beck CT. Essentials of nursing research: Appraising evidence for nursing practice (9th ed.). Lippincott Williams \& Wilkins; 2018.

[30] Aysha ZMS, El-Din SMA, Attia NR, et al. Efficacy of implementing nursing care protocol on the incidence of ventilator associated pneumonia in Intensive Care Unit at Tanta emergency hospital. Journal of American Science. 2016; 12(2): 40-52.

[31] Ghoneim AHA, El-Komy HMA, Gad DM, et al. Assessment of weaning failure in chronic obstructive pulmonary disease patients under mechanical ventilation in Zagazig University Hospitals. Egyptian Journal of Chest Diseases and Tuberculosis. 2017; 66(1): 65-74. https://doi.org/10.1016/j.ejcdt.2016.01.013

[32] Mohamed KAE. Compliance with VAP bundle implementation and its effectiveness on surgical and medical sub-population in adult ICU. Egyptian Journal of Chest Diseases and Tuberculosis. 2014; 63(1): 9-14. https://doi.org/10.1016/j.ejcdt.2013.10.019

[33] Teasdale G, Jennett B. Assessment and prognosis of coma after head injury. Acta neurochirurgica. 1976; 34(1): 45-55. PMid: 961490. https://doi.org/10.1007/BF01405862

[34] Sessler CN, Gosnell MS, Grap MJ, et al. The Richmond AgitationSedation Scale: validity and reliability in adult intensive care unit patients. American Journal of Respiratory and Critical Care Medicine. 2002; 166(10): 1338-1344. PMid: 12421743. https: //doi.org/10.1164/rccm.2107138

[35] Keykha A, Khoshfetrat M, Dahmardeh AR, et al. Success rate of weaning from mechanical ventilation in patients admitted to the intensive care unit with utilization burn's wean assessment program. Archives of Anesthesiology and Critical Care. 2017; 3(2): 319-323.

[36] Keykha A, Khoshfetrat M, Dahmardeh AR, et al. Success rate of weaning from mechanical ventilation in patients admitted to the intensive care unit with utilization burn's wean assessment program. Archives of Anesthesiology and Critical Care. 2017; 3(2): 319-323.

[37] Montasser M. Decreasing the incidence of ventilator associated pneumonia with complete adherence to its prevention bundle. Al-Azhar Medical Journal. 2017; 46(2): 425-432. https ://doi .org/10.1 2816/0038264

[38] Mohamed MA, Ismail MF, Elshora AE, et al. Intensive care unit of Chest Department Zagazig University Hospitals' experience in management of acute exacerbations of chronic obstructive pulmonary disease. Egyptian Journal of Chest Diseases and Tuberculosis. 2013 62(2): 229-234. https://doi.org/10.1016/j.ejcdt.2013.0 4.006

[39] Salwa AG, Romeh OLAA, Youssef MM, et al. Effectiveness of Noninvasive Ventilation in Acute Respiratory Failure. The Medical Journal of Cairo University. 2019; 87(March): 713-722. https : //doi.org/10.21608/mjcu.2019.52528
[40] Khalil MM, Abd Elfattah NM, El-Qusy AS. Assessment of the outcome of mechanically ventilated chronic obstructive pulmonary disease patients admitted in the respiratory ICU in Ain Shams University Hospital. Egyptian Journal of Bronchology. 2014; 8(2): 138-142. https://doi.org/10.4103/1687-8426.145708

[41] Nafae RM, El-Shahat HM, Shehata SM, et al. Effect of Multimodal Physiotherapy on Outcome of Mechanically Ventilated Patients at Zagazig University Respiratory Intensive Care Unit in (20142015). Zagazig University Medical Journal. 2018; 24(3): 178-191. https://doi.org/10.21608/zumj.2018.13092

[42] Bruno CM, Valenti M. Acid-base disorders in patients with chronic obstructive pulmonary disease: a pathophysiological review. Journal of Biomedicine and Biotechnology. 2012. PMid: 22500110. https://doi.org/10.1155/2012/915150

[43] Lim TK, Chee CB, Chow P, et al. Ministry of health clinical practice guidelines: chronic obstructive pulmonary disease. Singapore Med J. 2018; 59(2): 76-86. PMid: 29568852. https ://doi .org/10.116 22/smedj. 2018015

[44] International Diabetes Federation. IDF diabetes atlas (9th ed.). Dunia: IDF; 2019.

[45] World Health Organization (WHO). How many people have hypertension over the world? 2021. Available from: www . pinterest.co $\mathrm{m} /$ worldhealthorganization

[46] Mahishale V, Angadi N, Metgudmath V, et al. Prevalence and impact of diabetes, hypertension, and cardiovascular diseases in chronic obstructive pulmonary diseases: A hospital-based cross-section study Journal of Translational Internal Medicine. 2015; 3(4): 155-160. PMid: 27847906. https://doi.org/10.1515/jtim-2015-001 9

[47] Ho TW, Huang CT, Ruan SY, et al. Diabetes mellitus in patients with chronic obstructive pulmonary disease-The impact on mortality. PLoS One. 2017; 12(4): e0175794. PMid: 28410410. https: //doi.org/10.1371/journal.pone.0175794

[48] Sawalha S, Hedman L, Backman H, et al. The impact of comorbidities on mortality among men and women with COPD: report from the OLIN COPD study. Therapeutic Advances in Respiratory Disease. 2019; 13: 1753466619860058. PMid: 31291820. https://doi.org/10.1177/1753466619860058

[49] Mao X, Liang C, Niu H, et al. Outcomes associated with comorbid diabetes among patients with COPD exacerbation: findings from the ACURE registry. Respiratory Research. 2021; 22(1): 1-10. PMid: 33407433. https://doi.org/10.1186/s12931-020-01607-6

[50] Dale CR, Kannas DA, Fan VS, et al. Improved analgesia, sedation, and delirium protocol associated with decreased duration of delirium and mechanical ventilation. Annals of the American Thoracic Society. 2014; 11(3): 367-374. PMid: 24597599. https: //doi.org/10.1513/AnnalsATS.201306-2100C

[51] Keykhah A. The effect of the sedation protocol on the level of consciousness in ventilator-dependent trauma patients hospitalized in Intensive Care Unit (ICU). Medical-Surgical Nursing Journal. 2015; 4(1).

[52] Carraway JS, Carraway II MW, Truelove Jr. CA. Nursing implementation of a validated agitation and sedation scale: An evaluation of its outcomes on ventilator days and ICU length of stay. Applied Nursing Research. 2021; 57: 151372. PMid: 33172729. https://doi.org/10.1016/j.apnr.2020.151372

[53] Taran Z, Namadian M, Faghihzadeh S, et al. The effect of sedation protocol using Richmond Agitation-Sedation Scale (RASS) on some clinical outcomes of mechanically ventilated patients in intensive care units: a randomized clinical trial. Journal of Caring Sciences. 2019; 8(4): 199. PMid: 31915621. https ://doi .org/10.15171 /jcs.2019.028 
[54] Yousefi H, Toghyani F, Yazdannik AR, et al. Effect of using Richmond Agitation Sedation Scale on duration of mechanical ventilation, type and dosage of sedation on hospitalized patients in intensive care units. Iranian Journal of Nursing and Midwifery Research. 2015; 20(6): 700. PMid: 26793256. https : //doi .org/10.4103/1735 $-9066.170008$

[55] Klompas M, Li L, Kleinman K, et al. Associations between ventilator bundle components and outcomes. JAMA Internal Medicine. 2016; 176(9): 1277-1283. PMid: 27428482. https://doi.org/10.100 1/jamainternmed.2016. 2427

[56] Yılmaz C, Girgin NK, Özdemir N, et al. The effect of nursingimplemented sedation on the duration of mechanical ventilation in the ICU. Turkish Journal of Trauma and Emergency Surgery. 2010; 16(6): 521-526.

[57] Jeong ES, Lee K. Clinical application of modified burns wean assessment program scores at first spontaneous breathing trial in weaning patients from mechanical ventilation. Acute and Critical Care. 2018; 33(4): 260. PMid: 31723894. https://doi.org/10.4266/acc. 2018.00276

[58] Lavallée JF, Gray TA, Dumville J, et al. The effects of care bundles on patient outcomes: a systematic review and meta-analysis. Implementation Science. 2017; 12(1): 1-13. PMid: 29187217. https://doi.org/10.1186/s13012-017-0670-0

[59] Eweas AS, Mohammad SY, Sayyed JSA, et al. Application of Modified Ventilator Bundle and Its Effect on Weaning Among Mechani- cally Ventilated Patients. 2. Assessment of Applying Clinical Audit for Pregnant Woman with Iron Deficiency Anemia. 2020; 15.

[60] El-Sharkawy MAE, Mohamed WY, Ali NS. Effect of ventilator bundle implementation on weaning indicator among mechanically ventilated patients at a selected private healthcare sector. Egyptian Nursing Journal. 2017; 14(1): 50. https://doi .org/10.4103/ENJ.ENJ_ 10_17

[61] Samra SR, Sherif DM, Elokda SA. Impact of VAP bundle adherence among ventilated critically ill patients and its effectiveness in adult ICU. Egyptian Journal of Chest Diseases and Tuberculosis. 2017; 66(1): 81-86. https://doi.org/10.1016/j.ejcdt. 2016 .08 .010

[62] Karagözoğlu Ş, Yildiz FT, Gürsoy S, et al. The effect of bundle adaptation control on vap speed and length of hospital stay in avoiding the ventilator associated pneumonia (VAP) at Anesthesia Intensive Care Unit. Int J Nurs Clin Pract. 2018; 5: 295-301. Available from: https://doi.org/10.15344/2394-4978/2018/295

[63] Braun SE. The Effects of Staff Education on Ventilator-Associated Pneumonia in the Itensive Care Unit: A Literature Review. 2019.

[64] Parisi M, Gerovasili V, Dimopoulos S, et al. Use of ventilator bundle and staff education to decrease ventilator-associated pneumonia in intensive care patients. Critical Care Nurse. 2016; 36(5): e1-e7. PMid: 27694363. https://doi.org/10.4037/ccn2016520 